\title{
Association between Discharge Pharmacist Counselling Techniques and Hospital Readmission Rate
}

\author{
Rayf Abulezz ${ }^{1 *}$, Thamer Alaifan² ${ }^{2}$ Aeshah Al-Azmi ${ }^{1}$, Abdul Salam $^{3}$ and Ahmed Attar \\ ${ }^{1}$ King Saud bin Abdulaziz University for Health Sciences, Saudi Arabia \\ ${ }^{2}$ Schulich School of Medicine \& Dentistry, Canada \\ ${ }^{3}$ King Abdullah International Medical Research Center-Eastern Region, Saudi Arabia \\ ${ }^{4}$ McMaster University, Canada
}

Submission: March 22, 2018; Published: April 27, 2018

*Corresponding author: Rayf Abulezz, King Saud bin Abdulaziz University for Health Sciences, Saudi Arabia, Tel: +966-14-866-9999. Ext: 68237; Email: AbualezzRS@NGHA.MED.SA

Abstract

Background: The Indian Health Services counseling technique has been used for decades, but no study has assessed its effect on patient health outcome.

Objective: We evaluated the impact of a new discharge counseling technique on patients' readmission rate and on identifying medication discrepancies during discharge.

Methods: A retrospective investigational study was conducted to compare the 30 days readmission rate among patients subjected to the new counseling method with those of the standard methods (primary objective). Data for 30-day readmission rate were collected from patients' medical records and the hospital electronic system. The secondary objective was to evaluate the frequency and types of drug-related problems detected at the time of discharge among both groups. All patients who were counseled using the new counseling technique during December 2011 to January 2012 and the standard techniques during October and November 2011 were included.

Results: We identified 191 patients counseled using the standard technique and 233 patients counseled using the new technique. The readmission rate was lower by approximately $34 \%$ for the new counseling technique (15.8\%) compared with those subjected to the standard one (24.1\%; P =0.034; OR: 1.681; 95\% confidence interval (CI), 1.037-2.724). The new technique helped the pharmacists to identify the discrepancies more frequently $(20.6 \%)$ compared with the standard technique $(5.2 \% ; \mathrm{P}<0.001)$. There were statistically significant differences regarding the type of diagnosis, gender and number of medication used between the two counseling technique. Multiple logistic regression models identified that type of counseling, and type of diagnosis was significant independent factor associated with readmission within 30 days after discharge.

Conclusion: Our study showed that the new discharge counseling technique was associated with a lower readmission rate and improved detection of identified discrepancies 4 times more than the standard technique for identified high-risk adult and pediatric patients. Larger-scale prospective studies are needed to confirm this finding.

Keywords: Counseling; Patient readmission; United states indian health service; Confidence interval; Drug-related problems

Abbreviations: DRPs: Drug-Related Problems; ED: Emergency Department; SD: Standard Deviation; OR: Odds Ratio; CI : Confidence Interval

\section{Introduction}

Drug-related problems (DRPs) are among the main cause of avoidable hospital readmissions and emergency department (ED) visits Lack of proper patient counseling and medication review at the time of discharge can lead to many medication discrepancies and noncompliance, which can lead to medication adverse drug reactions and hospital readmission [1,2]. After hospital discharge, readmissions and ED visits are likely to decrease by $30 \%$ when patients receive proper instructions on their medication use Many studies have been conducted to examine the effect of pharmacist counseling on patient readmission rates, patient compliance, medication adverse effects and patient knowledge about his/her medication [3-12]. Some of these studies found statistical difference decrease in the readmission rate with the discharge pharmacist counseling, while other were not able to show this significant decrease in the readmission rate $[11,12]$. None of these studies have evaluated the effect of counseling techniques on patient outcome, even though many counseling techniques are taught to pharmacy students during their studies. 


\section{Global Journal of Pharmacy \& Pharmaceutical Sciences}

Our health care institute is a 500-bed tertiary care facility that treats both pediatric and adult patients with complex medical and surgical problems. The services include the largest oncology service in the western part of our country. Since 1990, we have used various pharmacist counseling services, more recently based on multiple criteria (Table 1). The standard counseling technique used by our pharmacy staff was through providing basic medication information (e.g. medication name, indication, frequency, and route of administration) and then ask the patient if he or she had any questions. This standard counseling technique did not allow the pharmacist to evaluate the patient's knowledge about his/her medication(s), nor did it allow the pharmacist to know the reason for admission to focus the counseling in a specific way. The pharmacy administration decided to change the discharge counseling technique to a newer one based on major pharmacy references through using openended questions (based on the modified Indian Health Service Table 1: Criteria's for patient counseling. techniques) and planning for discharge medication counseling $[13,14]$. The Indian Health Service counseling techniques consist of 3 primary questions, and we added 4 extra questions based on a major pharmacy reference [14] This new technique included 5 main elements that we assessed during the study period. The first element was to establish rapport with the patient. The second element was to apply the REAP mnemonic (Reason for admission; Evaluate current medication regimen for DRPs, including noncompliance; Assess the patient's knowledge base and skills to self-medicate and assess compliance-promoting strategies; and Plan to avoid DRPs after discharge). The third element was to use open-ended questions (based on modified Indian Health Service techniques). The fourth element was to use strategies to address and improve adherence, and the final element was the closing part where the patient had a chance to ask any other questions.

\section{The Drug that have Narrow Therapeutic Index and are Especially Dangerous if the Least Mistake is Made}

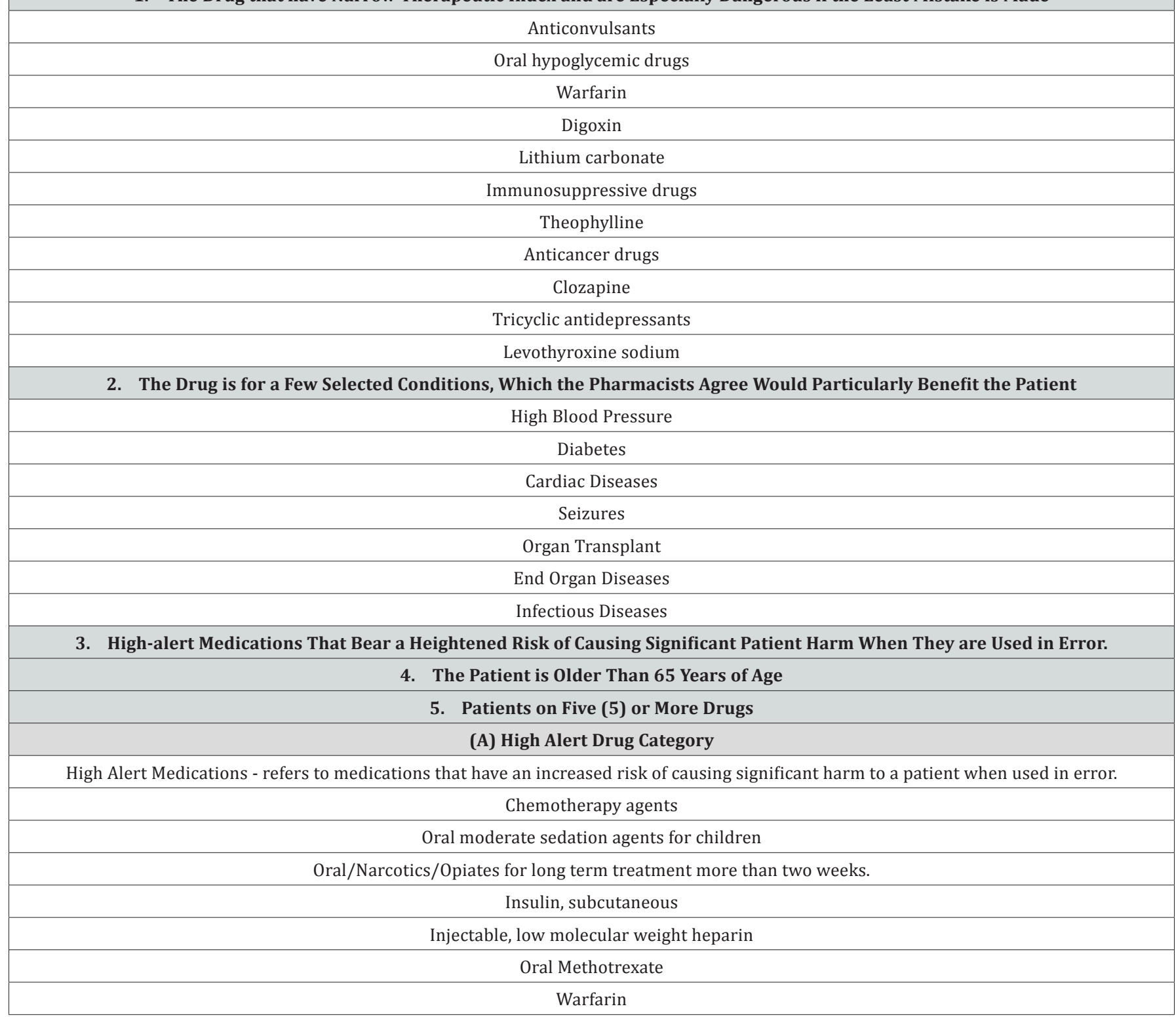




\section{Global Journal of Pharmacy \& Pharmaceutical Sciences}

Table 2: Checklist for patient counselling interview guide.

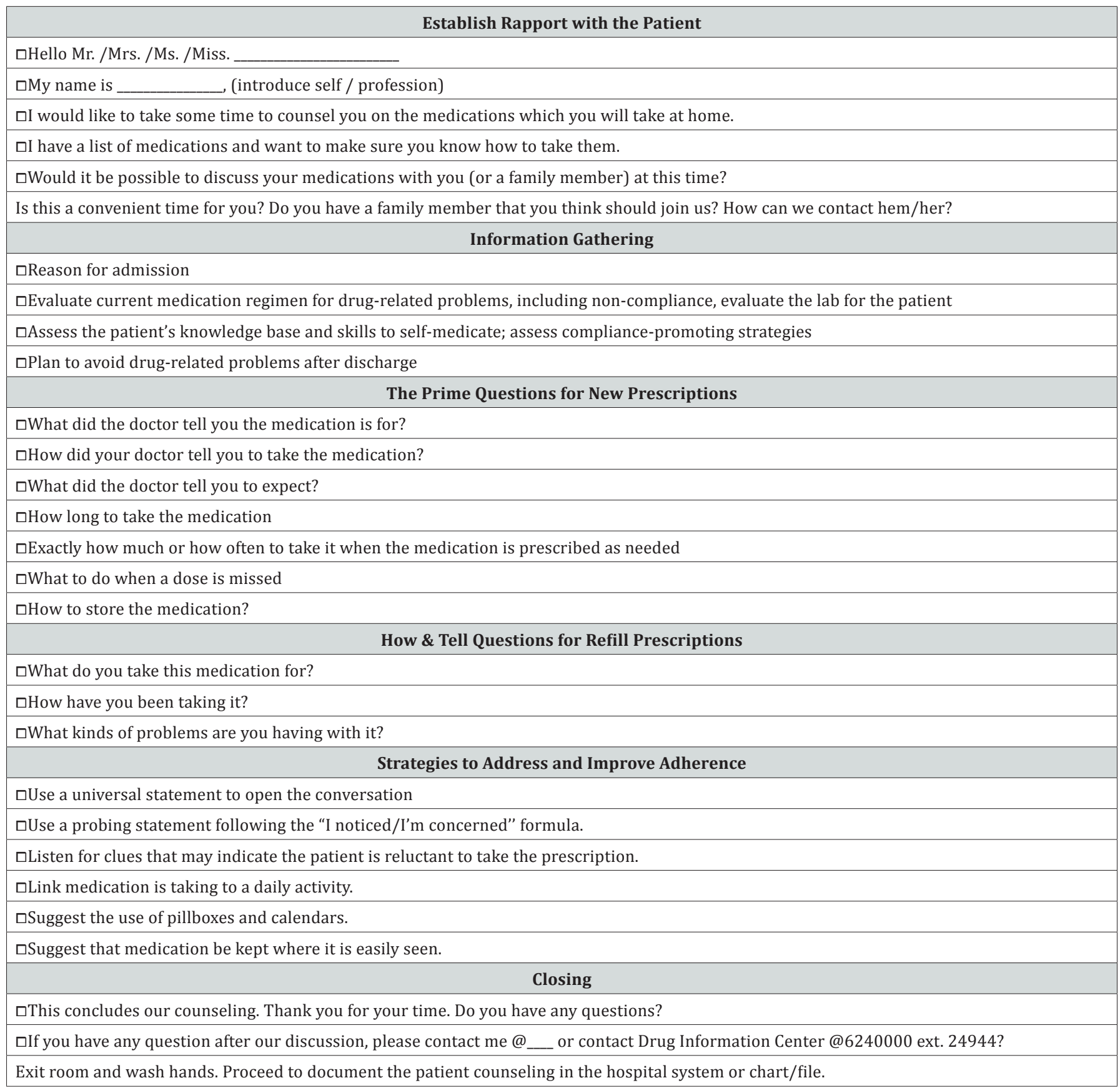

The pharmacy administration chose two pharmacy practice residents to apply this technique during their inpatient rotation. A checklist (Table 2) with the above criteria was created for them to follow during their counseling. During their counseling, the two pharmacy residents were able to identify many important medication-related errors that we thought might have an impact on hospital readmission rate.

In this study, we evaluated the impact of this new discharge counseling technique on patients' readmission rate and identified medication errors during discharge compared with the standard technique.

\section{Materials and Methods}

The procedures followed were in accordance with the standards of the institution's ethical committee and approval. The study was a retrospective investigational study that compared 30-day readmission rate (as the main patient outcome) among those who experienced the new counseling method versus those who experienced the standard method. Data for 30-day readmission rate were collected from patients' medical records and the hospital electronic system. The secondary objective was to evaluate the frequency and types of DRPs detected by the pharmacist/pharmacy resident at the time of discharge among 


\section{Global Journal of Pharmacy \& Pharmaceutical Sciences}

both groups. The discrepancies were categorized according to the intervention type. Medication discrepancies were identified and collected through pharmacy therapeutic intervention documentation system/software, which is part of the hospital program for electronic intervention recording by pharmacists.

Inclusion criteria included all adult and pediatric patients (or their caregivers in the case of pediatric patients) who were counseled by the two pharmacy residents using the new counseling technique during December 2011 to January 2012 and all patients who were counseled using the standard techniques for the months of October and November 2011. This was documented on paper-based pharmacy records for both groups. Per pharmacy policy, patients who will be counseled by pharmacists must fall into one of the specific categories in Table 1. We excluded patients who did not meet the pharmacy criteria for counseling. The co investigators (pharmacy and medical residents) independently collected available data from hospital and pharmacist records for each group separately. A medical resident was given an orientation, access to therapeutic intervention documentation system, and copies of the pharmacy resident data. The collected data were then exchanged and reviewed by the other co-investigator twice, and an agreement was made for every subject for all data collected. All study contributors resolved any disagreement by consensus.

Planned readmission, such as booked admissions for chemotherapy cycles or planned procedures, was not counted as readmission. Unintentional discrepancies at the time of discharge were identified and calculated based on the following discrepancy classifications: drug omission, wrong dose, missed medical problem (medical condition without drug therapy), allergy, and others (e.g. duplicate therapy, pharmacist mistake). The collected data were more objective, including the readmission rate plus the number of discrepancies above. The information collected for each group included the age, sex, number of medications, diagnoses (as a subjective consensus to simplify classification, we classified the diagnosis as internal medicine, oncology, or surgery), readmission rate within 30 days, admission type (full admission or ER admission), number of discrepancies identified, and types of discrepancies.

\section{Statistical Analysis}

Descriptive results for all quantitative variables (e.g. age in years) were presented as mean \pm standard deviation (SD), while numbers (percentages) were reported for all qualitative variables (e.g. gender). Bi-variate analysis was performed using the Pearson Chi square test and independent sample $t$ test whenever appropriate to compare the all the demographic (e.g. age, gender) and clinical characteristics (e.g. diagnosis, number of medication, discrepancy, and readmission within 30 days after discharge) between two types of counseling (standard vs new). Univariate logistic regression analysis was used to assess the relationships of readmission within 30 days after discharge, discrepancy, and type of counseling (new vs. standard). The odds ratio (OR) and 95\% confidence interval (CI) for odds ratio were reported. A multivariate analysis was also performed using a multiple logistic regression analysis to assess the relationship between the dependent variable (readmission rate within 30 days after discharge) and the independent variable (counseling type: standard vs new) after adjusting for potential confounders such as age, sex, diagnosis, number of identified discrepancies, and number of medications. A 2-sided $\mathrm{P}$ value $<0.05$ was considered statistically significant. All statistical analyses were performed using Statistical Package for Social Sciences (SPSS) version 20.0 .

\section{Results}

We identified 191 patients counseled by a pharmacist using the standard technique and 233 patients counseled by the pharmacy residents using the new technique; these figures were based on the time frame of the study and were not calculated beforehand. These numbers provide a power of greater than $90 \%$ to detect a difference of $10 \%$ or more between the two groups at $5 \%$ level of significance.

\section{Characteristics of the study groups}

Table 3: Characteristics of the patients and the type of counselling.

\begin{tabular}{|c|c|c|c|}
\hline \multirow{2}{*}{ Factor } & \multicolumn{2}{|c|}{ Counseling Type } & \multirow{2}{*}{ P-value $\Psi$} \\
\hline & Standard ${ }^{(\mathrm{n}=191)}$ & New ${ }^{(n=233)}$ & \\
\hline \multicolumn{4}{|c|}{ Diagnosis } \\
\hline Medicine* & $91(47.6 \%)$ & 79 (33.9\%) & \\
\hline Surgical & $57(29.8 \%)$ & $80(34.3 \%)$ & 0.012 \\
\hline Oncology* & $43(22.5 \%)$ & $74(31.8 \%)$ & \\
\hline \multicolumn{4}{|c|}{ Age in years } \\
\hline$<18$ & $25(13.1 \%)$ & $42(18.0 \%)$ & 0.166 \\
\hline$\geq 18$ & $166(86.9 \%)$ & $191(82.0 \%)$ & \\
\hline \multicolumn{4}{|c|}{ Gender } \\
\hline Male & $74(38.7 \%)$ & $116(49.8 \%)$ & 0.023 \\
\hline Number of Medication at discharge & $07.3 \pm 04.6$ & $08.4 \pm 04.4$ & $0.011 \S$ \\
\hline
\end{tabular}




\section{Global Journal of Pharmacy \& Pharmaceutical Sciences}

Results are expressed as number (percentage) and median (Inter quartile range).

$\Psi \mathrm{P}$-value has been calculated using Pearson Chi-Square test..

$\S \mathrm{P}$-value has been calculated using Independent Sample t-test.

*Medicine vs. Oncology $p=0.005$; Medicine vs. Surgery $p=0.038$; Surgery vs. Oncology $p=0.430$ using multiple comparison with Bonferroni correction test.

The average age of children between the new intervention group and the standard intervention group is approximately similar at the statistical significant level of (P 0.48). Similarly there was no statistically significant difference in the mean age of adult patients between the new intervention group (59.7 \pm 16.7 years) and the standard intervention group (56.9 \pm 18.1 years). More males were included in the new intervention than those who were subjected to the standard intervention, and this difference was statistically significant $(\mathrm{P}=0.023)$. Although patients were almost evenly distributed according to the type of diagnosis of patients with the new counseling technique, it was not the case among patients who experienced the standard counseling technique; almost half of these patients had a diagnosis that fell under the internal medicine category and the rest were distributed over the oncology and surgery categories, and these differences were statistically significant ( $\mathrm{P}$ 0.012) (Table 3). Multiple comparison analysis using Bonferroni correction test showed that the proportion of patients received standard counseling were significantly more among the medicine $(47.6 \%)$ vs. Oncology (22.5\%), and vs. Surgery $(29.8 \%)$ at the statistical significant level of $\mathrm{P}=0.005$ and $\mathrm{P}=0.038$ respectively. The number of medications used by patients was higher among patients who were counseled by the new counseling technique compared with the standard technique, and this difference was statistically significant at $\mathrm{P}=0.011$ (Table 3).

\section{Number of medication errors}

The discrepancies were more frequently detected (4 times) among patients who were subjected to the new counseling technique than among those who experienced the standard counseling technique, and this difference was statistically significant $(\mathrm{P}<0.05)$. It was found that most of the discrepancies detected among patients counseled with the standard technique were incorrect doses, whereas missed medical problems and drug omission were the most frequently detected discrepancies in the group counseled with the new technique, with each discrepancy observed for (Table 4).

Table 4: Number and types of identified discrepancies during discharge according to the type of counseling technique.

\begin{tabular}{|c|c|c|c|c|c|}
\hline \multirow{2}{*}{ Factor } & \multicolumn{2}{|c|}{ Counseling Type } & \multirow{2}{*}{ OR } & \multirow{2}{*}{$95 \% \mathrm{CI}$} & \multirow{2}{*}{ P-value $\Psi$} \\
\hline & Standard $(\mathrm{n}=191)$ & New $^{(\mathrm{n}=233)}$ & & & \\
\hline \multicolumn{6}{|c|}{ Discrepancy found } \\
\hline Yes & $10(5.2 \%)$ & $48(20.6 \%)$ & 0.213 & $0.105-0.434$ & $<0.001$ \\
\hline \multicolumn{6}{|c|}{ Type of Discrepancy } \\
\hline Drug Omission & 0 & $14(6.0 \%)$ & & & \\
\hline Wrong Dose & $7(3.7 \%)$ & $13(5.6 \%)$ & & & \\
\hline Missed Medical Problem & 0 & $14(6.0 \%)$ & & & $-\cdots$ \\
\hline Allergy & 0 & $1(0.4 \%)$ & & & \\
\hline Other & $3(1.6 \%)$ & $4(1.7 \%)$ & & & \\
\hline
\end{tabular}

\section{Readmission rates within $\mathbf{3 0}$ days after discharge}

The readmission rate was significantly higher among those who were counseled by the standard counseling technique $(24.1 \% ; \mathrm{n}=46)$ compared with those subjected to the newer one $(15.8 \% ; n=37 ;$ P 0.034$)$, with odds ratio of 1.681 (95\% CI: $1.04-$
2.7) using univariate logistic regression analysis indicate that the odds of readmission within 30 days after discharge among patients who were received standard counseling technique is $68 \%$ more than those patients who were received new counseling technique (Table 5).

Table 5: Relationship between counseling type and readmission rate within 30 days after discharge.

\begin{tabular}{|c|c|c|c|c|c|}
\hline \multirow{2}{*}{ Factor } & \multicolumn{2}{|c|}{ Counseling Type } & \multirow{2}{*}{ OR } & \multirow{2}{*}{$95 \%$ CI } & \multirow{2}{*}{ P-value $\psi$} \\
\hline & Standard $(\mathrm{n}=191)$ & New $(n=233)$ & & & \\
\hline Readmission within 30 days after discharged & $46(24.1 \%)$ & $37(15.8 \%)$ & 1.681 & $1.037-2.724$ & 0.034 \\
\hline
\end{tabular}

${ }^{*}$ Results are expressed as number (percentage), Odds ratio (OR) with 95\% Confidence Interval $(\mathrm{Cl})$.

$\Psi \mathrm{P}$-value has been calculated using pearson chi-square test.

A step by step multiple logistic regression models was used to identify if the type of counseling technique (standard vs. new technique) is statistically significant independent factor associated with the dependent variable (readmission within 30 days after discharge) after adjusting for potential confounders such as age, gender, diagnosis, number of identified discrepancies, and number of medications. The statistically significant independent factors associated with readmission within 30 days after discharge included: the type of counseling 


\section{Global Journal of Pharmacy \& Pharmaceutical Sciences}

technique, and type of diagnosis (Table 6). The adjusted odds ratio for standard type of counseling was 1.921 (95\% confidence interval, 1.152-3.203), with $\mathrm{P}=0.012$, which indicates that the adjusted odds of readmission within 30 days after discharge among those patients who were received standard counseling technique is almost two times more than among those patients who were received new counseling technique after adjusting for independent factors (Table 6).

Table 6: Multiple logistics regression to identify significant independent factors associated with readmission rate within 30 days after discharge

\begin{tabular}{|c|c|c|c|}
\hline Factor & Adjusted Odds Ratio & $\mathbf{9 5} \%$ for Adjusted Odds Ratio & P-value¥ \\
\hline Type of Counseling (old) & 1.921 & $1.152-3.203$ & 0.012 \\
\hline Diagnosis & & & \\
\hline Surgical & 1 & & 0.074 \\
\hline Medical & 1.904 & $1.921-7.965$ & $<0.001$ \\
\hline Oncology & 3.912 & & \\
\hline
\end{tabular}

Results are expressed as Odds ratio (OR) with 95\% Confidence Interval $(\mathrm{Cl})$. The dependent variable is readmission rate within 30 days after discharge and independent variables are type of counseling, age in years, and diagnosis.

$¥ P$-value has been calculated using wald test.

\section{Discussion}

The standard method of medication counseling is based on the pharmacist providing information and the patient listening to instructions. The pharmacist may clarify the patient's knowledge and understanding by asking "Did you understand what I said?" or "Do you have any question for me?" These direct instructions and close-ended questions do not verify whether the patient knows how to use his or her medication appropriately. The Indian Health Services counseling technique has 3 openended questions that use the effective educational approach of "teaching back" to verify the patient's understanding of his/her medications and fill in any gaps. This counseling technique has been used for decades in the United States but was not known in our country and our students and pharmacists did not learn this technique during their studies in national pharmacy schools. We did not find studies assessing this counseling technique in terms of patient outcomes or the effect of the REAP mnemonic approach on readmission rate. We decided to study the modified Indian Health questions (the same questions plus another 4 questions), which were found in one reference [13] in addition to other techniques from another reference [14]: establishing rapport, applying the REAP mnemonic, using strategies to address and improve adherence, and finally using the closing technique. Although it was not mentioned in the major references, our residents also evaluated patient laboratory values as part of evaluating the current medication regimen in the REAP mnemonic, which helped in identifying many serious errors before patient discharge.

Our study has many advantages. The new discharge counseling technique was associated with a statistically significant 36\% lower readmission rate. Although there was a statistically significant difference in the average number of medications for each group, this could indicate another advantage of our study: the average number of medications was higher in the new counseling technique group, which may mean that patients in our group were sicker and that their chance of noncompliance and readmission might have been higher. Even though it was not statistically significant, the admission rate for inpatient (i.e. not only ER visit) in the standard technique group was higher than that in the new technique group, which may mean that the patients were really sick and required real admission to the hospital rather than just an ER visit. The number of discrepancies identified was 4 times higher in the new counseling technique compared with the standard one, and it was also statistically significant. The new counseling technique improved the detection of missed medical problems and drug omissions that might have had an impact on the readmission rate for these patients.

The drawback of our study is that the two groups were not identical regarding the sex of patients and their diagnoses, and this is mostly because our study was retrospective, but the readmission was still statistically significantly associated with counseling type after adjusting for these confounding factors. Another drawback is that the study represents the experience of a single center. A prospective controlled study will be needed to confirm our findings. The two different groups conducting the education are not limitation for our study since the pharmacy residents were already registered pharmacists and they were in their first year of residency which was manly pharmaceutical care rotation.

\section{Conclusion}

Our study showed that the new discharge counseling technique was associated with a lower readmission rate and improved detection of identified discrepancies 4 times higher than the standard technique for identified high-risk patients. Prospective studies to confirm the benefit of this new counseling technique are needed before recommending it to similar health care institutes. The retrospective nature of this study is a major drawback.

\section{References}

1. Boutwell A, Hwu S (2009) Effective interventions to reduce rehospitalizations: a survey of the published evidence. MA: Institute for Healthcare Improvement, Cambridge, USA, pp. 1-139. 
2. Budnitz DS, Lovegrove MC, Shehab N, Chesley LR (2011) Emergency hospitalizations for adverse drug events in older Americans. N Engl J Med 365: 2002-2012.

3. Brian WJ, Veerappa KC, Anthony D, Greenwald JL, Sanchez GM, et al. (2009) A reengineered hospital discharge program to decrease rehospitalization. Ann Intern Med 150(3): 178-187.

4. Schnipper JL, Kirwin JL, Cotugno MC, Wahlstrom SA, Brown BA, et al. (2006) Role of pharmacist counseling in preventing adverse drug events after hospitalization. Arch Intern Med 166(5): 565-571.

5. Walker PC, Bernstein SJ, Jones J, Piersma J, Kim HW, et al. (2009) Impact of a pharmacist-facilitated hospital discharge program: a quasiexperimental study. Arch Intern Med 169(21): 2003-2010.

6. Stowasser D, Collins DM, Stowasser MA (2002) A randomized controlled trial of medication liaison services: patient outcomes. J Pharm Prac \& Res 32(2): 133-140.

7. Smith L, McGowan L, Moss-Barclay C, Wheater J, Knass D, et al. (1997) An investigation of hospital generated pharmaceutical care when patients are discharged home from hospital. Br J Clin Pharmacol 44(5): 163-165.

8. Bolas H, Brookes K, Scott M, McElnay J (2004) Evaluation of a hospitalbased community liaison pharmacy service in Northern Ireland. Pharm World Sci 26(2): 114-120.
9. Lipton HL, Bird JA (1994) The impact of clinical pharmacists' consultations on geriatric patients' compliance and medical care use: a randomized controlled trial. Gerontologist 34(3): 307-315.

10. Johnston M, Clarke A, Mundy K, Cromarty E, Ridout K, et al. (1986) Facilitating comprehension of discharge medication in elderly patients. Age Ageing 15(5): 304-306.

11. Nazareth I, Burton A, Shulman S, Smith P, Haines A, et al. (2001) A pharmacy discharge plan for hospitalized elderly patients: a randomized controlled trial. Age Ageing 30(1): 33-40.

12. Al-Rashed SA, Wright DJ, Roebuck N, Sunter W, Chrystyn H, et al. (2002) The value of inpatient pharmaceutical counseling to elderly patients prior to discharge. Br J Clin Pharmacol 54(6): 657-664.

13. MacLean LG (2010) Patient Consultation in the Cycle of Patient Care. In: Stein SM (Ed.), Pharmacy practice manual: a guide to the clinical experience. ( $3^{\text {rd }}$ edn), Lippincott Williams \& Wilkins, Philadelphia, USA, pp. 566-577.

14. Herrier RN (2009) Case Studies in Patient Communication. In: Schwinghammer TL, Koehler JM (Eds.), Pharmacotherapy casebook: a patient-focused approach, ( $8^{\text {th }}$ edn), McGraw-Hill Professional, New York, USA, pp. 11-20.

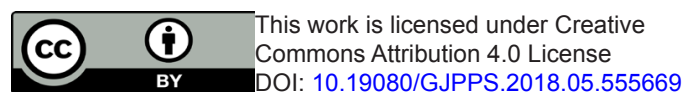

- Quality Editorial service

- Swift Peer Review

- Reprints availability

- E-prints Service

- Manuscript Podcast for convenient understanding

- Global attainment for your research

- Manuscript accessibility in different formats

( Pdf, E-pub, Full Text, Audio)

- Unceasing customer service

Track the below URL for one-step submission https://juniperpublishers.com/online-submission.php 